\title{
Thermoluminescence characteristics of copper activated calcium borate nanocrystals
}

(CaB407:Cu)

\begin{abstract}
The copper activated calcium tetraborate $(\mathrm{CaB} 4 \mathrm{O} 7: \mathrm{Cu})$ nanophosphor was synthesized by a combination of facile co-precipitation and thermal treatment methods for the first time. Thermoluminescence and dosimetric characteristics of the gamma irradiated $\mathrm{CaB} 4 \mathrm{O} 7: \mathrm{Cu}$ nanophosphor was reported. The glow curves shows two well resolved TL peaks centered at about $120^{\circ} \mathrm{C}$ and $260{ }^{\circ} \mathrm{C}$. The copper concentration was varied from 1 to $3 \mathrm{~mol} \%$ and it was found that the nanocrystalline $\mathrm{CaB} 4 \mathrm{O} 7: \mathrm{Cu}$ with a dopant concentration of $2 \mathrm{~mol} \%$ has the highest sensitivity among the other dopant concentrations. The results demonstrated that copper can enhance TL efficiency to 2.26 times more than that of un-doped nanocrystalline samples. Moreover, the dose response of the dosimetric peak at $260{ }^{\circ} \mathrm{C}$ follows a good linearity up to $3 \mathrm{kGy}$ whereas the linearity of lower temperature peak at $120{ }^{\circ} \mathrm{C}$ extended up to $30 \mathrm{~Gy}$. The linearity characteristic of the present nanophosphor suggests it as a candidate towards dosimetric applications.
\end{abstract}

Keyword: Copper; Calcium tetraborate; Nanophosphor; Thermoluminescence; Coprecipitation; Radiation dose 